https://doi.org/10.15407/ujpe63.4.285

A.I. IVANISIK

Taras Shevchenko National University of Kyiv, Faculty of Radio Physics, Electronics and Computer Systems

(4g, Academician Glushkov Ave., Kyiv 03127, Ukraine; e-mail: aivan@univ.kiev.ua)

\title{
SCATTERING OF GINZBURG-FRANK \\ AND CHERENKOV TYPES UNDER SELF-FOCUSING OF NANOSECOND LASER PULSES IN LIQUIDS ${ }^{1}$
}

\begin{abstract}
We study the dynamics of nonlinear optical processes such as self-focusing, self-phase modulation, and stimulated Raman scattering in Kerr-liquids under the nanosecond laser pulse excitation. The results prove the existence of the transition Ginzburg-Frank-type effect, which promotes the appearance of new spectral components of the laser radiation at the medium boundary. The generation of extended anti-Stokes frequency-angular bands of stimulated Raman scattering is explained. When the velocity of a self-focusing focal spot matches the phase velocity of the non-linear polarization at the anti-Stokes Raman frequency and the phase velocity of the scattered axial radiation, the most intense frequency-angular bands appear. They are described by the equations typical of the Cherenkov radiation.
\end{abstract}

Ke yw ords: self-focusing, self-phase modulation, stimulated Raman scattering.

\section{Introduction}

The self-focusing (SF) of laser pulses in the nanosecond range in a Kerr medium leads to the movement of a focal spot [1]. The focal spot speed $v_{\mathrm{fp}}$ is defined by the laser pulse envelope. At the front and back of a pulse, $v_{\mathrm{fp}}$ takes positive and negative values and is not limited by the speed of light in vacuum [2].

In the practical aspect, SF creates a new situation the dynamics of nonlinear optical processes such as the self-phase modulation (SPM) and the stimulated Raman scattering (SRS), which cannot be achieved within other technical methods.

Previously, we identified the stop point location of a focal spot [3], possibility of Cherenkov-type radiation of SRS under SF [4], effect of SF on angular spectra of SRS [5], angle-selective inverted SRS [6], frequency dependence of anti-Stokes SRS on the focal spot speed in the approach of "ideal thin lens"

(c) A.I. IVANISIK, 2018

ISSN 2071-0194. Ukr. J. Phys. 2018. Vol. 63, No. 4
[7], transition effect of SPM [8], and physical mechanism of anti-Stokes SRS of the Cherenkov type under SPM [9].

Now, it is possible to state the principles of the Ginzburg-Frank transition and the Cherenkov (or Vavilov-Cherenkov) superluminal scattering [10] under SF of nanosecond laser pulses in Kerr liquids.

\section{Consideration and Analysis}

A simplified scheme for describing the processes is presented in Fig. 1. The focal spot has velocity [2] $v_{\mathrm{fp}}=v_{\mathrm{fd}} v_{\mathrm{g} L} /\left(v_{\mathrm{fd}}+v_{\mathrm{g} L}\right)$, which can exceed the light speed $c$ in vacuum $\left(v_{\mathrm{fd}}-\right.$ velocity of focal $z_{\mathrm{f}}$ distance change, $v_{\mathrm{g} L}$ - group speed of laser radiation).

The laser spot has velocity $v_{\mathrm{fp}}=v_{\mathrm{fd}}=0$ for the top of a laser pulse. At this stop-point of a laser spot, classical SRS can be observed, which has asymmetric

1 The paper was presented at the XXIII Galyna Puchkovska International School-Seminar "Spectroscopy of Molecules and Crystals". 


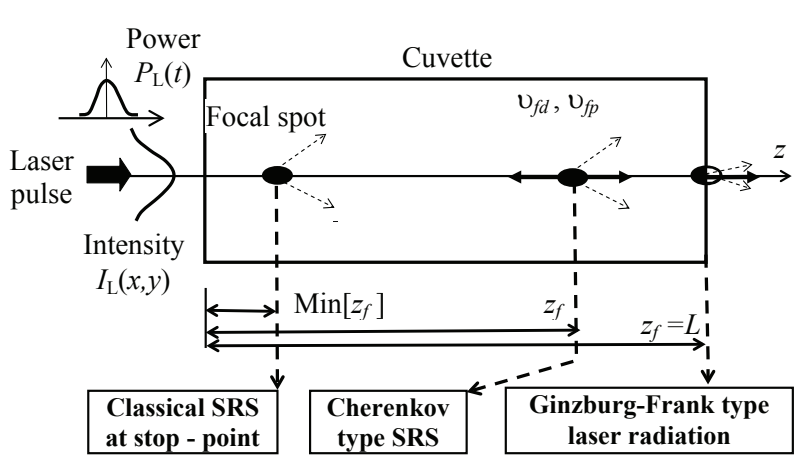

Fig. 1. Simplified scheme for describing the processes
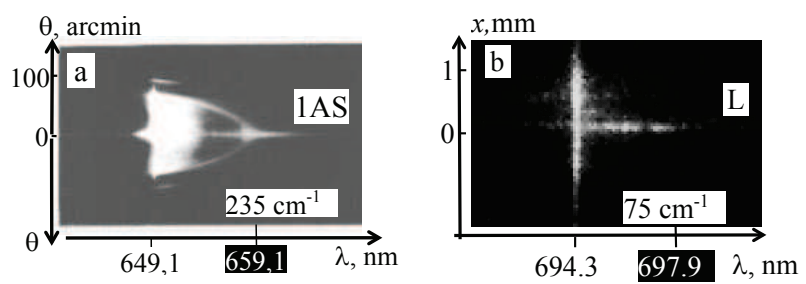

Fig. 2. Experimental frequency-angular spectrum of the Cherenkov-type scattering $(a)$ in the coordinates angel $(\theta)$ - wavelength $(\lambda)$ and frequency-spatial spectrum of the transitiontype scattering $(b)$ in the coordinates: lateral coordinate $(x)$ wavelength $(\lambda)$ for a ruby laser at $20 \mathrm{~ns}, 0.5 \mathrm{~J}$ pulse in toluen

indicatrix for the parametric scattering. However, the indicatrix asymmetry is another question.

When the focal spot is closer to the exit of a cuvette, the Cherenkov-type superluminal scattering can be observed for parametric SRS. The experimental frequency-angular spectrum of the Cherenkovtype scattering is presented in Fig. 2, $a$ for the first anti-Stokes (1AS) SRS in toluene under the excitation by a ruby laser in the coordinates: scattering angle $(\theta)$ - wavelength $(\lambda)$. As the focal spot crosses the exit boundary of a cuvette, Ginzburg-Frank transition-type scattering is observed for the laser radiation. An experimental frequency-spatial spectrum of the transition-type scattering is presented in Fig. $2, b$ for the ruby laser radiation $(L)$ in the coordinates: lateral coordinate $(x)$ - wavelength $(\lambda)$. The maximum Stokes frequency shifts in reverse centimeters $\left(\mathrm{cm}^{-1}\right)$ are indicated in Fig. 2.

A general qualitative similarity for the axial scattering is observed. This is a result of the mutual SPMeffect of the laser radiation. The maximum Stokes frequency shift $\Delta \nu_{1 \mathrm{AS}}$ for the first anti-Stokes SRS is about 3 times more than the laser shift $\Delta \nu_{L}$, because $\nu_{1 \mathrm{AS}}=2 \nu_{\mathrm{L}}-\nu_{\mathrm{S}}$ and $\Delta \nu_{1 \mathrm{AS}}=2 \Delta \nu_{L}+\Delta \nu_{\mathrm{S}}=3 \Delta \nu_{L}$ (here $\nu_{\mathrm{S}}$ is the Stokes component frequency). The maximum Stokes frequency shift $\Delta \nu_{2}$ AS for the second anti-Stokes SRS is about 7 times more than $\Delta \nu_{L}$, seeing $\nu_{2 \mathrm{AS}}=2 \nu_{1 \mathrm{AS}}-\nu_{L}, \quad \Delta \nu_{2 \mathrm{AS}}=2 \Delta \nu_{1 \mathrm{AS}}+\Delta \nu_{L}=$ $=7 \Delta \nu_{L}$.

For the maximal value $\Delta \nu_{L}$ of the frequency Stokes-shift caused by the transition effect for the laser radiation, it is possible to derive the analytical expression:

$\Delta \nu_{L} \approx \nu_{L} \Delta n_{\mathrm{f}}\{z=L\} \frac{v_{\mathrm{fd}}\{z=L\}}{c}$,

where $z$ is a longitudinal coordinate, $\Delta n_{\mathrm{f}}\{z=L\}$ is an increment of the refractive index at the focal point at the distance $z=L$ (at the medium boundary), $v_{\mathrm{fd}}\{z=L\}-$ a velocity of the focal point at the medium boundary (without considering the difference between times, which are necessary for the pulse fragments to reach the focal point), and $c$ - the speed of light.

The maximum energy density of axial $(\theta=0) 1 \mathrm{AS}$ radiation is located at the frequency determined by conditions, which are similar to those for the Cherenkov radiation: equality of the phase velocities of electromagnetic waves $v_{\mathrm{ph}}\{\omega\}$ at the frequency $\omega$ and the phase velocity $v_{\text {ap0 }}$ of a polarization at the anti-Stokes Raman frequency $\omega_{a}$. The axial frequency shift in toluene is $\left(\omega\{\theta=0\}-\omega_{a}\right) / 2 \pi c=$ $=-197 \mathrm{~cm}^{-1}$.

For $\theta \neq 0$ and $v_{\mathrm{fp}}=v_{\mathrm{ap} 0}$, the frequency-angular branches are related by the expression

$\cos \theta \approx v_{\mathrm{ph}}(\omega) / v_{\mathrm{ap} 0}$

that gives a parabola for $\cos \theta \approx 1-\theta^{2} / 2$.

\section{Conclusions}

The Ginzburg-Frank (transition effect) - type and Cherenkov (superluminal effect) - type radiations are analyzed at the nanosecond laser pulse excitation in the spectra of a laser and SRS.

1. At the transition effect, the maximum frequency shift of the laser radiation appears, when the focal point of self-focusing intersects the exit boundary of the medium, and the phase delay of SFM before and after the focal point is uncompensated.

2. The SRS Cherenkov-type radiation appears at the coincidence of self-focusing focal point speed, the

ISSN 2071-0194. Ukr. J. Phys. 2018. Vol. 63, No. 4 
phase velocity of a nonlinear polarization at the antiStokes Raman frequency and the phase velocity of scattered SRS-radiation. This is a result of the superluminal speed of the focal point and the velocity of a nonlinear polarization.

It will be if interest to analyze the mutual impact of the Ginzburg-Frank and Cherenkov effects on SRS.

1. Y.R. Shen. The Principles of Nonlinear Optics (Wileyinterscience, 2003).

2. A. Ivanisik, P. Korotkov, G. Ponezha. Temporal dynamics of focal point location under self-focusing of nanosecond laser pulses. Ukr. J. Phys. Opt. 15, 1 (2014).

3. A.I. Ivanisik, V.I. Malyi, G.V. Ponezha.The spatialangular structure of the anti-Stokes emission under the stimulated Raman scattering of light in a Kerr fluid. Optika i Spektroskopiya 80, 212 (1996).

4. A.I. Ivanisik, V.I. Malyi, G.V. Ponezha. Cherenkov-type radiation under conditions of Raman light scattering in self-focusing liquids. Optics and Spectroscopy 82, 410 (1997).

5. A.I. Ivanisik, V.I. Malyi, G.V. Ponezha. On the influence of a self-focusing on the angular spectra of SRS. Opitka $i$ Spektroskopiya 85, 88 (1998); Optics and Spectroscopy 85, 78 (1998).

6. A.I. Ivanisik, V.I. Malyi, G.V. Ponezha. The spectralangular manifestations of a competition of the Raman and parametric processes under SRS in self-focusing media. Opitka i Spektroskopiya 85, 512 (1998); Optics and Spectroscopy 85, 469 (1998).

7. A.I. Ivanisik, G.V. Ponezha. Spectrum of anti-Stokes stimulated Raman scattering from the moving focal regions of self-focusing. Optika i Spektroskopiya 90, 699 (2001); Optics and Spectroscopy 90, 625 (2001).

8. S.O. Dudka, A.I. Ivanisik, A.V. Konopatskiy, P.A. Korotkov. Transition effect at the medium vacuum interface under the self-phase modulation of a light pulse. Ukr. J. Phys. 51, 140 (2006).

9. A.I. Ivanisik, O.Iu. Isaienko, P.A. Korotkov, G.V. Ponezha. Phase modulated parametric anti-Stokes stimulated Raman scattering of Cherenkov-type in self-focusing areas of exciting radiation. Ukr. J. Phys. 57, 1000 (2012).

10. I.M. Frank. Vavilov-Cherenkov Radiation:Theoretical Aspects (Nauka, 1988).

Received 26.11.17

\section{A.I. Іванісік}

РОЗСІЮВАННЯ ГІНЗБУРГА-ФРАНКА ТА

ЧЕРЕНКОВСЬКОГО ТИПІВ ЗА САМОФОКУСУВАННЯ НАНОСЕКУНДНИХ ЛАЗЕРНИХ ІМПУЛЬСІВ У РІДИНАХ

$\mathrm{P}$ е $з$ ю м е

Досліджено динаміку нелінійно-оптичних процесів (самофокусування, фазова самомодуляція, вимушене комбінаційне розсіювання) у керівських рідинах за дії наносекундних лазерних імпульсів. Результати доводять наявність перехідного ефекту типу Гінзбурга-Франка, який породжує нові спектральні компоненти лазерного випромінювання на межі середовища. Пояснено генерацію протяжних частотно-кутових смуг вимушеного комбінаційного розсіювання. У випадку збігання швидкості фокальної точки 3 фазовою швидкістю нелінійної поляризації на антистоксовій комбінаційній частоті та фазовою швидкістю розсіяного аксіального випромінювання виникають найінтенсивніші смуги, які описуються рівняннями, характерними для черенковського випромінювання. 